\title{
Study on Prescribing Pattern of Antihypertensive Drugs in a Tertiary Care Hospital
}

\author{
Prabhakar Adake, Nagpati Prabhakar Bhat", Roopa P Nayak, Hafis TK, Bhagyashree A, Prajna V Raj \\ Department of Pharmacology, Yenepoya Medical College, Yenepoya University, Mangalore, India \\ *Corresponding Author: npbhat17@gmail.com
}

Copyright $\bigcirc 2017$ by authors, all rights reserved. Authors agree that this article remains permanently open access under the terms of the Creative Commons Attribution License 4.0 International License

\begin{abstract}
Objective: To analyze prescription pattern of antihypertensive drugs in patients with hypertension alone and with coexisting diseases. Methodology: A descriptive cross- sectional study was conducted in outpatient department of tertiary care hospital in south India. A total of 286 prescriptions of patients diagnosed to have hypertension with or without coexisting diseases were collected. Details of prescriptions were entered in the preformed pro forma and analyzed. Result: The study included 138 (48.25\%) male and $148(51.75 \%)$ female. Out of 286 hypertensives, 122 (42.66\%) patients were having co-existing type 2 diabetes mellitus (T2DM). And remaining 164 patients (57.34\%) were only hypertensives. Out of 286 patients, 227 (79.31\%) patients were on monotherapy, $49(17.13 \%)$ were on dual therapy and remaining 10 patients were on triple anti-hypertensive drugs. Among 150 antihypertensive drugs that are prescribed for hypertensive patients withT2DM, 57 (38\%) were calcium channel blocker (CCB), 40 (26.66\%) were angiotensin converting enzyme inhibitors (ACEI), 31 $(20.66 \%)$ were angiotensin receptor blockers (ARB), 13 $(8.66 \%)$ were diuretics and remaining $9(6 \%)$ were beta blockers. Similarly, among 206 antihypertensive drugs prescribed for hypertension alone patients, $97(47 \%)$ were CCB, 37 (17.96\%) were ACEI, 31 (15\%) were ARB, 26 $(12.62 \%)$ were diuretics and remaining $15(7.28 \%)$ were beta blockers. Conclusion: The study has shown that majority of patients were on monotherapy $(79.31 \%)$ and calcium channel blockers were commonly prescribed for hypertension in patients with or without type 2 diabetes mellitus followed by ACE inhibitors, ARB and beta blockers.
\end{abstract}

Keywords Antihypertensive Drugs, Prescription Pattern Analysis, Cross Sectional Study

\section{Introduction}

Hypertension (HTN) is the commonest chronic medical condition responsible for coronary artery disease, stroke, chronic kidney disease and peripheral vascular diseases. [1]
Nearly $26 \%$ of adult population suffering from hypertension in worldwide. [2] About $33 \%$ of urban and $25 \%$ of rural population affected by hypertension in India. According to World Health Organization, hypertension is one of the important causes for premature death in worldwide [3].

The definition of hypertension as released by the seventh report of the Joint National Committee on Prevention, Detection, Evaluation and Treatment of High Blood Pressure (JNC 7) is systolic blood pressure (SBP) $\geq 140 \mathrm{mmHg}$ or diastolic blood pressure (DBP) $\geq 90 \mathrm{~mm} \mathrm{Hg}$, which simplifies hypertension classification by including only stage I (SBP 140-159 mm Hg or DBP 90-99) or stage II (SBP 160 $\mathrm{mm} \mathrm{Hg}$ or higher or DBP $100 \mathrm{~mm} \mathrm{Hg}$ or higher). Perhaps the most important change is the new classification of "pre-hypertension" (SBP 120-139 mm Hg or DBP 80-89 $\mathrm{mm} \mathrm{Hg}$ ), which combines the normal and high normal categories of the previous JNC VI report, in the recognition of the fact that even these levels of BP confer an increased risk of the development of hypertension and future cardiovascular events. $[4,5]$ HTN is usually asymptomatic and its diagnosis is mainly through screening, or when a person is seeking healthcare for an unrelated problem. Some proportion of hypertensive report headaches (particularly in the morning hours at the back of the head and), as well as lightheadedness, vertigo, tinnitus, altered vision or fainting episodes [6].

The primary goal of management of HTN is to prevent morbidity and mortality associated with it. Majority of hypertensive patients require two or more antihypertensive medications. Thiazide diuretics, $\beta$-blockers, angiotensin converting enzyme inhibitors (ACEIs), angiotensin receptor blockers (ARB) and calcium channel blockers (CCB) all have been shown to reduce complications of hypertension and can be used for initial management of HTN.

Availability of numerous antihypertensive drugs gives treating physician several options to individualize the therapy. [7] Due to this reason there can be change in the prescribing pattern from patient to patient and physician to physician. General principles of antihypertensive therapy conforming to the guidelines of JNC VII and WHO \& International Society of Hypertension (ISH) are considered. 
[8]

Rational drug prescribing is defined as the use of the least number of drugs to obtain the best possible effect in the shortest period and at a reasonable cost [9]. Measurement of drug usage pattern in health care not only describes the behavior of prescribers but also the extent of polypharmacy and the problems associated with it.

\section{Objectives}

To analyze prescription pattern of antihypertensive drugs in patients with hypertension alone and with coexisting diseases.

\section{Materials and Methods}

This descriptive cross- sectional study was conducted in outpatient department of General medicine, Yenepoya Medical College, Mangalore from January 2017 to March 2017. Ethical approval was obtained from Institutional Ethics Committee before starting the study. Sample size was calculated based on the average number of hypertensive patients visiting General medicine outpatient department of Yenepoya Medical College Hospital per day. During the period of 3 months, a total of 286 prescriptions (calculated sample size was 250) of patients diagnosed to have hypertension with or without coexisting diseases were collected. Informed consent was obtained from the participants. Details of prescriptions of the patients were entered in the preformed pro forma and analyzed.

\subsection{Inclusion Criteria}

Known hypertensive patients (with or without coexisting diseases) of either sex aged between 25-90 years of age.

\subsection{Analysis}

Data will be analyzed and results are expressed in percentages.

\section{Results}

A total of 286 prescriptions were collected from the hypertensive patients attending the out-patient department of General Medicine. The study included 138 (48.25\%) male and $148(51.75 \%)$ female individuals (Table 1). The age range was from 25 to 86 years old. Total number of antihypertensive drugs was found to be 356 for 286 patients and average number of drugs per prescription was 1.24 in this present study.
Table 1. Table showing the demographic profiles of all the hypertensive patients

\begin{tabular}{|c|c|c|c|}
\hline Gender & Number & Percentage & Age range \\
\hline Male & 138 & 48.25 & $30-83$ Years \\
\hline Female & 148 & 51.75 & $25-86$ Years \\
\hline Total & 286 & 100 & \\
\hline
\end{tabular}

Out of 286 hypertensive patients, 122 (42.66\%) patients were also suffering type 2 diabetes mellitus. And remaining 164 patients $(57.34 \%)$ were receiving only anti-hypertensive medications (Table 2).

Table 2. Table showing the details of hypertensive patients with co-existing type 2 diabetes mellitus.

\begin{tabular}{|c|c|c|}
\hline Disease & Number & Percentage \\
\hline Hypertension alone & 164 & 57.34 \\
\hline Hypertension with diabetes & 122 & 42.66 \\
\hline Total & 286 & 100 \\
\hline
\end{tabular}

Table 3 shows prescription details of hypertensive patients without co-existing diabetes mellitus. Out of 164 hypertensive alone patients, 125 patients $(76.21 \%)$ were on monotherapy, 31 patients were on dual therapy and remaining 8 patients were on triple antihypertensive therapy.

Table 3. Table showing the prescription details of antihypertensive agents in hypertensive patients without co-existing type 2 diabetes mellitus.

\begin{tabular}{|c|c|c|}
\hline Prescription type & Number & Percentage \\
\hline Mono-therapy & 125 & 79.21 \\
\hline Dual-therapy & 31 & 18.91 \\
\hline Triple therapy & 08 & 4.88 \\
\hline Total & 164 & 100 \\
\hline
\end{tabular}

Similarly, table 4 shows prescription details of hypertensive patients with co-existing diabetes mellitus patients. Out of 286 hypertensive patients, around 227 $(79.31 \%)$ patients were on single drug for hypertension. And $49 \quad(17.13 \%)$ individuals were prescribed dual antihypertensive agents. Whereas, remaining 10 patients were on triple anti-hypertensive medications.

Table 4. Table showing the prescription details of antihypertensive agents in all the hypertensive patients

\begin{tabular}{|c|c|c|}
\hline Prescription type & Number & Percentage \\
\hline Mono-therapy & 227 & 79.31 \\
\hline Dual-therapy & 49 & 17.13 \\
\hline Triple therapy & 10 & 3.46 \\
\hline Total & 286 & 100 \\
\hline
\end{tabular}

A total of 150 antihypertensive drugs were prescribed for 122 hypertensive patients with co-existing type 2 diabetes mellitus. Among 150 antihypertensive drugs, 57 (38\%) were calcium channel blocker (CCB), $40 \quad(26.66 \%)$ were angiotensin converting enzyme inhibitors (ACEI), 31 $(20.66 \%)$ were angiotensin receptor blockers (ARB), 13 $(8.66 \%)$ were diuretics and remaining $9(6 \%)$ were beta 
blocker for the management of hypertension (Table 5).

Table 5. Table showing the details of antihypertensive agents in hypertensive patients with co-existing type 2 diabetes mellitus.

\begin{tabular}{|c|c|c|}
\hline Group & Number & Percentage \\
\hline Calcium channel blockers & 57 & 38 \\
\hline ACEI & 40 & 26.66 \\
\hline ARB & 31 & 20.66 \\
\hline Diuretics & 13 & 8.66 \\
\hline Beta blockers & 09 & 6 \\
\hline Total & 150 & 100 \\
\hline
\end{tabular}

Similarly, a total of 206 antihypertensive drugs were prescribed for 164 hypertensive patients without any co-existing diseases. Among 206 antihypertensive drugs, 97 (47\%) were calcium channel blocker (CCB), 37 (17.96\%) were angiotensin converting enzyme inhibitors (ACEI), 31 $(15 \%)$ were angiotensin receptor blockers (ARB), 26 $(12.62 \%)$ were diuretics and remaining $15(7.28 \%)$ were beta blocker for the management of hypertension (Table 6).

Table 6. Table showing the details of antihypertensive agents in hypertension alone patients

\begin{tabular}{|c|c|c|}
\hline Group & Number & Percentage \\
\hline Calcium channel blockers & 97 & 47 \\
\hline ACEI & 37 & 17.96 \\
\hline ARB & 31 & 15 \\
\hline Diuretics & 26 & 12.62 \\
\hline Beta blockers & 15 & 7.28 \\
\hline Total & 206 & 100 \\
\hline
\end{tabular}

\section{Discussion}

A prescription based on study is considered to be one of the most effective methods to assess and evaluate drug utilization of medication. Prescription by the clinician may be taken as a reflection of his/her attitude towards the disease and role of the drug in treatment. It also provides insight on the nature of healthcare delivery system. The objectives of antihypertensive treatment are to control hypertension and also to reduce mortality and morbidity associated with hypertension. Most of the hypertensive individuals require two or more drugs for the proper control of blood pressure. Sometimes presence of co-existing disease affects the selection of antihypertensive drugs. [10]

The United States Joint National Committee on the prevention, detection, evaluation and treatment of high blood pressure states that in the absence of compelling or specific indications for another drug, a diuretic or $\beta$-blocker should be chosen as initial therapy for hypertension [11]. These recommendations were seconded by the British Hypertension Society [12].

Use of multiple drugs in combinations has become routine to control hypertension in patients with diabetes. Several studies have demonstrated that most patients with hypertension could achieve and sustain adequate blood pressure control only with the use of multiple antihypertensive drugs [13]. However, in our study majority of the patients in our study were on monotherapy $(79.31 \%)$ followed by dual-therapy $(17.13 \%)$ and triple therapy $(3.46 \%)$. Present study has shown that round $42.66 \%$ of hypertensives have co-existing type 2 diabetes mellitus. These findings are similar to the previous studies done in India.[14] Several studies in India have shown an increasing trend in the prevalence of HTN among urban adults. HTN is responsible for $57 \%$ of all stroke mortality and $24 \%$ of all CAD mortality in India. [15] HTN substantially increases the risk of both macrovascular and microvascular complications in DM.

In our study, calcium channel blockers are most commonly used antihypertensive agents both in hypertension alone $(47 \%)$ and with coexisting type 2 diabetes mellitus patients (38\%). ACE inhibitors and ARB agents are preferred next to calcium channel blockers. These findings coincides with the study done by Pang-Hsiang Lui et al. [16] Beta blockers and diuretics are less commonly used antihypertensive agents in our study.

\section{Conclusions}

Present study interprets the current prescribing pattern of antihypertensive agents at our study site. CCB are the leading group of antihypertensive agents followed by ACEI, $\mathrm{ARB}$, Beta blockers and diuretics.

\section{Acknowledgements}

Authors are thankful to all the post graduates of Pharmacology, Yenepoya Medical College, Mangalore for their support.

\section{Conflicts of Interest: Nil}

\section{REFERENCES}

[1] Lewington S, Clarke R, Qizilbash, N, Peto, R and Collins R. Prospective Studies, Collaboration. Age-specific relevance of usual blood pressure to vascular mortality: a meta-analysis of individual data for one million adults in 61 prospective studies. Lancet 2002; 360: 1903-13.

[2] Kearney PM, Whelton M, Reynolds K, Muntner P, Whelton PK, He J et al. Global burden of hypertension: analysis of worldwide data. Lancet 2005; 365 (9455): 217-23.

[3] Raghupathy Anchala, Nanda K. Kannuri, Hira Pant, Hassan Khan, Oscar H. Franco, Emanuele Di Angelantonio et al. Hypertension in India: a systematic review and meta-analysis of prevalence, awareness, and control of hypertension. J Hypertens. 2014;32 (6):1170-7. 
[4] Vasan RS, Larson MG, Leip EP, Kannel WB, Levy D. Assessment of frequency of progression to hypertension in non-hypertensive participants in the Framingham Heart Study. Lancet 2001; 358:1682-1686.

[5] Vasan RS, Larson MG, Leip EP, Evans JC, O'Donnell CJ, Kannel WB, et al. Impact of high-normal blood pressure on the risk of cardiovascular disease. N Engl J Med 2001; 345:1291-1297.

[6] Fisher ND, Williams GH. Hypertensive vascular disease. In Kasper DL, Braunwald E, Fauci AS, et al. Harrison's Principles of Internal Medicine. 16th ed. New York, NY: McGraw-Hill.2005; pp. 1463-81.

[7] Pai PG, Shenoy J, Sanji N. Prescribing Patterns of antihypertensive drugs in a South Indian tertiary care hospital. Drug Invention Today 2011, 3(4), 38-40.

[8] Haslett C, Chilvers ER, Hunter JAA, Boon NA editors; Hypertension. Davidson's Principles and Practice of Medicine. 18th edition, Churchill Livingstone, 2000:216- 222.

[9] G.H. Rimoy, M. Justin-Temu and C. Nilay. Prescribing Patterns and Cost of Antihypertensive Drugs in Private Hospitals in Dares Salaam, Tanzania. East and Central African Journal of Pharmaceutical Sciences 2008; 11:69-73.

[10] Williams GH; Hypertensive Vascular Disease In: Harrison's Principles of Internal Medicine. Braunwald E, Fauci AS, Kasper DL, Hauser SL, Longo DL, Jamson JL (Eds). 15th edition, McGraw-Hill 2001:1414-1429
[11] Joint National Committee on Prevention, Detection, Evaluation and Treatment of High Blood Pressure, Arch. Intern. Med. 1997; 157: 2413- 2445.

[12] L. Ramsay, B. Williams, G. Johnston, G. MacGregor, L. Poston and J. Potten. Guidelines for management of hypertension: report of the third working party of the British Hypertension Society. J. Hum. Hypertens. 1999; 13: 569-592.

[13] C. E. Mogensen, S. Neldam, I. Tikkanen et al., "Randomised controlled trial of dual blockade of renin-angiotensin system in patients with hypertension, microalbuminuria, and noninsulin dependent diabetes: the candesartan and Lisinopril microalbuminuria (CALM) study," British Medical Journal, vol. 321, no. 7274, pp. 1440-1444, 2000

[14] JR Sowers, M Epstein, ED Frohlich. Diabetes, hypertension, and cardiovascular disease an update. Hypertension 2001;37(4): 1053-1059.

[15] V. Mohan, M. Deepa, S. Farooq, M. Datta, and R. Deepa, Prevalence, awareness and control of hypertension in Chennai: the Chennai Urban Rural Epidemiology Study (CURES-52). Journal of Association of Physicians of India 2007;55: 326332.

[16] Pang-Hsiang Liu, Jung-Der Wang. Antihypertensive medication prescription patterns and time trends for newly-diagnosed uncomplicated hypertension patients in Taiwan. BMC Health Services Research 2008; 8: 133-144. 